\title{
The Health Humanities and Camus's the Plague, Edited by Woods Nash, Kent, OH: Kent State University Press, 2019
}

\author{
Steven Wilson ${ }^{1}$ iD
}

Accepted: 1 October 2020 / Published online: 9 October 2020

(C) Springer Science+Business Media, LLC, part of Springer Nature 2020

In his opening to this impressive collection of eleven essays, Woods Nash makes a bold claim: "To introduce students to the interdisciplinary field of health humanities, I know of no better work of fiction than Albert Camus's The Plague" (1). Mark Orme, in his contribution, goes further still: "The Plague is undoubtedly one of the most important works to emerge from France in the mid-twentieth century" (83). Yet the bibliographies at the end of each chapter in this volume point us to the inescapable fact that few substantial, book-length studies of Camus's work have been produced in the last ten years and none on The Plague in the last twenty. Woods Nash's excellent edited volume therefore represents a timely and significant body of scholarship from three points of view. Firstly, it offers a fresh, innovative appraisal of The Plague's potential as an entry point into an exploration of issues of concern to the health humanities, including epidemics, bioethics, suffering, and (medical) care at a time when the novel is still too often read principally as an allegory of political invasion and occupation. Secondly, it brings together a rich array of interdisciplinary perspectives that challenge the reader to engage with the text from unusual standpoints, such as that of a medical student, a healthcare practitioner, a patient, a carer or, as Anoushka Sinha argues in a particularly striking piece in the book, all those who cross boundaries into those places and spaces where we experience "being uprooted," "disorder," and "unfamiliar landscapes" (97). In this way, Camus's text prompts us to seek affinity with patients and all those "whose experiences seem jarringly removed from our own" (97). Thirdly, the range of approaches contained within the volume, each focused on the same literary text, means that this book does not merely put in place the conditions that invite an interdisciplinary health humanities reading of The Plague; instead, it actively offers the reader the opportunity to be part of a compelling, engaging discussion as he or she navigates the volume and the issues explored therein.

Part of the reason for this is found in the deft way in which Nash has constructed the volume. The four sections - History; Philosophy; Literature and Other Media; Becoming a Health Professional - focus on different aspects of the text. The first situates The Plague in a range of pertinent contexts, including Camus's battle with tuberculosis, his engagement with

Steven Wilson

steven.wilson@qub.ac.uk

1 School of Arts, English and Languages, Queen's University Belfast, Belfast BT7 1NN, UK 
the French Resistance, and his familiarity with physicians. The essays in this section provide a solid foundation for more textual readings of the stigma of disease, suffering, vulnerability, healing, care, and physician identity in part two, which culminates fittingly in Orme's exhortation that The Plague "provides a number of templates for patients and clinicians dealing with the daily reality of illness and disease" (84). The third section segues neatly into the various displacements provoked by the literary text, be it in the reader who identifies with the exiled citizens of Oran or the multimedia echoes of the tropes of Camus's work in film (specifically, the 1995 movie Outbreak) and video game (the 2012 production of Plague, Inc.). Building on this, the fourth section opens with two chapters that consider, respectively, how the representations of disease and its effects in The Plague resonate with the realities of Ebola in West Africa, and with the suffering of a husband and wife as the latter undergoes multiple sclerosis in what is a particularly poignant and beautifully written essay. In the aftermath of reading about so many challenges posed by disease, the concluding piece offers some encouragement by picking up on one of the watchwords of our time, resilience, but sending the reader away on the hopeful note that far from being an "individualistic" pursuit, the paradigm of resilience portrayed in The Plague is a collective, social one from which we can all draw strength when confronted with adversity. The links between chapters that are accentuated by the volume's considered running order are further enhanced by two dexterous editorial judgements: essays occasionally make explicit reference to each other, suggesting contributors have read each others' work, and Nash provides a helpful summary at the beginning of each piece. These decisions allow for cohesion and concentration.

This is a compelling yet accessible study, which will be of interest to a multiplicity of readers - students of literature and/or medicine, healthcare professionals, and those drawn to philosophies of health and disease studies, for a start. In his introduction to the book, Nash writes: "More than seven decades after its publication, The Plague remains profoundly relevant to healthcare education and practice" (10). He cannot have known just how "relevant" it was to become to all of us seeking to better understand the realities of a deadly disease only a few months after his book went to press. As Stephen Metcalf put it in the Los Angeles Times (March 23, 2020), the "relevance" of The Plague "lashes you across the face" in these days of Covid-19. More prosaically, what we can say is that this archetype of "pestilence literature" has found millions of new readers across the world against the backdrop of infection, confinement and insecurity brought about by the current pandemic. The particular timeliness of Nash's book, while unforeseen, is inescapable. Yet, in its exploration of the human response to an epidemic, it sensitively redirects attention back to the transcending values and behaviors that lie at the heart of Camus's novel: vulnerability, empathy, solidarity, and resistance. This reader, for one, is glad that Nash's book was published when it was, for it provides a refreshing reminder that The Plague is so much more than "the Covid novel."

\section{Reference}

Metcalf, Stephen. 2020. “Albert Camus’ The Plague and our own Great Reset.” Los Angeles Times, March 23. https://www.latimes.com/entertainment-arts/books/story/2020-03-23/reading-camu-the-plague-amidcoronavirus.

Publisher's Note Springer Nature remains neutral with regard to jurisdictional claims in published maps and institutional affiliations. 